\title{
The Effect of Basic CPR Training on Adults' Knowledge and Performance in Rural Areas of Iran: A Quasi-Experimental Study
}

This article was published in the following Dove Press journal: Open Access Emergency Medicine

\author{
Zahra Khademian' \\ Zamanallah Hajinasab ${ }^{2}$ \\ Parisa Mansouri ${ }^{2}$ \\ 'Community-Based Psychiatric Care \\ Research Center, Department of \\ Nursing, School of Nursing and \\ Midwifery, Shiraz University of Medical \\ Sciences, Shiraz, Iran; ${ }^{2}$ Department of \\ Nursing, School of Nursing and \\ Midwifery, Shiraz University of Medical \\ Sciences, Shiraz, Iran
}

Introduction: Cardiac arrest happening outside the hospital, specifically in rural regions that are more distant from health centers, is a crucial issue in the health of individuals in those regions. Therefore, the ability of residents in those regions to do cardiopulmonary resuscitation (CPR) is very important in preventing death among people. This study aimed at determining the effect of basic CPR training on the adults' knowledge and performance in rural areas.

Methodology: This quasi-experimental study was conducted on 92 adults from rural areas of Shouraab Kohmareh-Sorkhi in Fars province, Iran, in September and October 2018. The samples were selected and divided into two groups using the simple random method. The data were collected using a demographic information form, knowledge questionnaire, and an observational checklist of CPR performance devised by the researcher. Basic teaching of CPR for the intervention group included two hours of oral teaching using lecture and question and answer as well as two hours of practical teaching using demonstration, practice on a manikin, provision of feedback, and correction of errors. The data were entered into the SPSS statistical software, version 21 and were analyzed using descriptive statistical tests, Kolmogorov-Smirnov test, independent $t$-test, chi-square test, Wilcoxon signed-rank test, and Mann-Whitney test.

Findings: The study results revealed that the intervention group's mean score of knowledge was significantly greater after the intervention $(6.78 \pm 1.23)$ compared to that at baseline $(2.78$ $\pm 1.74)$ and compared to the control group $(3.24 \pm 1.84)(\mathrm{p}<0.001)$. Additionally, the intervention group's mean score of performance was significantly greater after the intervention $(8.22$ $\pm 1.65)$ than that before the intervention $(0.8 \pm 0.77)$ and compared to the control group $(1.17$ $\pm 0.71)(\mathrm{p}<0.001)$.

Conclusion: According to the study findings, the villagers' performance and knowledge could be enhanced by teaching basic CPR techniques.

Trial Registration Number: IRCT20150714023199N3; date registered: 2018-05-06.

Keywords: adult, cardiopulmonary resuscitation, knowledge, rural population, observational checklist of CPR performance, teaching

\section{Introduction}

Cardiac arrest leads to death in thousands of people all around the world. ${ }^{1}$ It is an important cause of death in the United States, resulting in more than 395,000 annual out-of-hospital deaths. ${ }^{2,3}$ In Europe, the annual rate of death due to cardiac arrest has been reported to be about 700,000 people. ${ }^{4}$ Generally, cardiac arrest occurring outside the hospital and at home happens in every $20-140$ per 100,000 people 5 .
Community-Based Pahra Khademian

Research Center, Department of Nursing, School of Nursing and Midwifery, Shiraz University of Medical Sciences, Shiraz, Iran

Tel +9871 I 36474254

Fax +9871136474252

Email zahrakhademian@yahoo.com 
They make up about $50-70 \%$ of all cardiac arrests. ${ }^{6,7}$ In Iran, cardiovascular diseases are the leading cause of death, accounting for about $46 \%$ of all deaths and $20-23 \%$ of the disease burden. ${ }^{8,9}$

Cardiopulmonary Resuscitation (CPR) consists of measures that help maintain the vital performance of two major organs; i.e., heart and brain, in a person who has lost consciousness and increase his/her survival chance. ${ }^{10}$ Decreasing the time lapse between cardiac arrest and appropriate healthcare measures is one of the ways of cutting down the death toll caused by cardiac arrest. ${ }^{11}$ Initiating CPR measures by the people present at the scene of cardiac arrest can increase the survival likelihood by two times. ${ }^{12}$ Studies have shown that survival rate is two to three times more when bystanders initiate CPR outside the hospital compared to the times when no CPR is received. ${ }^{6}$ Yet, the success of CPR is low in a way that the success rate for cardiac arrests is less than $6 \%$ outside the hospital and less than $24 \%$ in the hospital. ${ }^{3,13}$ In seven Asian countries, the survival rate was between $0.5 \%$ and $8.5 \%$ after out-of-hospital cardiac arrests. ${ }^{14}$ Furthermore, only $11.8 \%$ of the patients suffering from cardiac arrest in an emergency unit in Tehran were discharged from hospital. ${ }^{15}$

The most important factor hindering the survival of patients suffering from cardiac arrest is the insufficiency of CPR done by the people present at the scene outside the hospital. ${ }^{16}$ The rate of CPR by bystanders was $30-50 \%$ among the individuals suffering from cardiac arrests in developed countries. ${ }^{17}$ In Asian countries, only 10.5$40.9 \%$ of the patients received CPR outside the hospital before the arrival of the emergency team. ${ }^{14}$ In a city in Iran also, only $3.6 \%$ of the bystanders provided CPR for patients out of hospitals. ${ }^{15}$ However, evidence has indicated that trained laypeople had more confidence and tendency to do $\mathrm{CPR}^{16,18,19}$ and showed an improved CPR quality. ${ }^{20}$ After dispatcher guidance in an urban area in Iran, the successful out-of-hospital resuscitations were increased from $28.1 \%$ to $32 \%$ and the survival rate increased from $56.5 \%$ to $72.4 \%{ }^{21}$

Success in doing CPR calls for the skill and competency of the people beside the patient. ${ }^{22}$ Various studies have revealed low knowledge and performance levels among students, ${ }^{23}$ soldiers, ${ }^{24}$ and laypeople. ${ }^{25}$ However, teaching basic CPR techniques enhanced the knowledge and performance levels in patients' entourages ${ }^{26}$ and high school students. ${ }^{11}$ Expert teaching also improved self-efficacy, which was associated with such learning outcomes as independence and confidence in applying what was learned. ${ }^{27}$ Teaching people in the society and developing their knowledge and performance could also play a significant role in survival after cardiac arrest. ${ }^{28}$ The American Heart Association (AHA) guidelines have also focused on educating the general public about $\mathrm{CPR}^{29}$

Rural areas encounter more problems regarding accessibility to healthcare facilities. Hence, as some studies have shown, the survival rate was lower in these regions compared to urban areas. ${ }^{30}$ In a national Korean study, $46.3 \%$ of bystanders in rural areas had performed out-ofhospital CPR. ${ }^{31}$ Furthermore, teaching students in villages to do CPR increased their knowledge. ${ }^{32}$ However, few studies have addressed the effect of teaching basic CPR techniques on adult villagers' knowledge and performance. It should be noted that having sufficient knowledge does not warrantee proper performance and it is necessary to improve individuals' performance, too. Given that rural inhabitants may have low health literacy, ${ }^{33}$ the importance of investigating the effects of education on their knowledge and performance in this regard has increased. With respect to the specific cultural-economic and social features in villages, the findings of the studies conducted so far cannot be generalized to other groups of people residing in these areas.

Shouraab Kohmareh-Sorkhi is one of the rural areas in Iran. This mountainous region has curving narrow impassable roads and driving in the foggy road is sometimes difficult in rainy weather. Therefore, it may be difficult to transfer patients and injured people to medical centers in emergency situations. Hence, at least one member of each family should be familiar with CPR to help other family members in critical situations. Considering the important role of bystanders' CPR and shortage of studies done in rural areas of the world, the present study aims to determine the effect of training basic CPR techniques on the adults' knowledge and performance in rural areas of Shouraab Kohmareh-Sorkhi in Iran.

\section{Methodology Design and Participants}

This quasi-experimental study was conducted in September and October 2018. This trial was conducted in accordance with the Declaration of Helsinki. The sample size was calculated based on the data from a pilot study for comparing the control and intervention groups regarding CPR knowledge. The post-intervention means and standard 
deviations of these two groups were $4.82 \pm 1.92$ and 3.46 \pm 1.64 , respectively. Considering $\alpha=0.05,1-\beta=0.9, \mathrm{~S} 1=1.92$, $\mathrm{S} 2=1.64, \mu 1=4.82$, and $\mu 2=3.46,37$ participants were estimated to be needed in each group. However, considering a possible dropout of $20 \%$, the sample size was determined to be 46 individuals in each group.

$$
n=\frac{\left(Z_{1-\frac{\alpha}{2}}+z_{1-\beta}\right)^{2}\left(s_{1}^{2}+s_{2}^{2}\right)}{d^{2}}=37
$$

The sample consisted of 92 adults residing in the rural areas of Shouraab Kohmareh-Sorkhi in Fars province, which were distant from the province capital. The inclusion criteria of the study were having the required mental and physical ability, having the reading and writing abilities, being willing to participate in the research project, filling out the consent form, and aging 18-55 years. The exclusion criteria were failing to complete the pretest or posttest completely and having participated in the previous research projects on CPR. The participants were selected among 13 villages in the region, and four villages were finally selected using simple random sampling. Again, using simple random sampling, two villages were allocated to the intervention group and two to the control group. The number of samples in each village depended on the number of families in that village. Then, based on the table of random numbers and village families lists, it was determined which family of each village could enter the study. Each family was required to introduce only one representative member to participate in the study. Eventually, there were 46 people in each group. All participants remained in the study and there was no attrition in the samples.

\section{Data Collection}

The study data were collected using a demographic information form, basic CPR knowledge questionnaire, and the observational checklist of CPR performance. The demographic information form included questions on gender, marital status, education level, occupation, having basic information about CPR, and having witnessed an individual's loss of consciousness. The basic CPR knowledge questionnaire consisted of 10 multiple-choice questions. Score 1 was given to each correct answer and score 0 was assigned to wrong answers or unanswered questions. Thus, the total score could range from 0 to 10 . The observational checklist of CPR performance included 12 items. Score 1 was given to each correct performance and score 0 to incorrect performance or non-performance. Hence, the total score could range from 0 to 12 .

The basic CPR knowledge questionnaire and the observational checklist of CPR performance were prepared according to the AHA guidelines (2015) for lay rescuers. ${ }^{34}$ The knowledge questionnaire contained questions about basic CPR, method of CPR, and managing a patient with airway obstruction with a foreign body. The observational checklist of CPR performance included five general dimensions as follows: assessing responsiveness, asking for help, determining the correct place for hands, doing hard and fast heart massage, and observing the order of basic CPR. The face and content validity of the basic CPR knowledge questionnaire and the observational checklist of CPR performance were confirmed by 10 experts. The Content Validity Ratio (CVR) was 0.987 for the knowledge questionnaire and 0.966 for the observational checklist of CPR performance. The inter-observer reliability of the observational checklist of CPR performance was 0.797 . In order to confirm the reliability of the knowledge questionnaire, it was completed by 30 people who had referred to the community health center in Shouraab Kohmareh-Sorkhi and the correlation coefficient was calculated to be 0.458 using the test-retest method.

The knowledge questionnaire was completed via interviews in the participants' houses before and after the intervention. In addition, the performance test was taken using training manikins (Ambu $\left.{ }^{\circledR} \mathrm{Man}\right)$ in the community health center of each village before and after the intervention. The post-tests for knowledge and performance were held eight weeks after the intervention.

\section{Intervention}

On the day of performing the intervention, the participants from both villages in the intervention group were invited to the village's central prayer room. In order to blind the study, the researcher's assistant who collected the data and the statistical analyst did not have any information about the people in the intervention and control groups. The intervention was done for the intervention group by the researcher based on the AHA guidelines (2015) for lay rescuers. The content included the importance of $\mathrm{CPR}$, how to deal with an unconscious person, how to check responsiveness, CPR steps, and first aids in airway obstruction with a foreign body. This program included two hours of oral teaching using lecture and questions and answers about CPR as well as two hours of practical 
teaching using demonstration, practicing basic CPR on a manikin (Ambu ${ }^{\circledR} \mathrm{Man}$ ), providing feedback, and correcting mistakes. Oral teaching was done simultaneously for male and female participants. However, male and female participants' practices were done separately. In order to provide all individuals with the opportunity to participate in the intervention, the teaching sessions were held in two sequential days. However, the control group did not receive any education.

\section{Data Analysis}

The collected data were analyzed using the SPSS software, version 21. The tests used for this analysis included descriptive statistics for describing the variables, $t$-test for comparing the two groups with regard to age, and Kolmogorov-Smirnov test for investigating the normality of the data. In addition, Mann-Whitney test was used to compare the two groups concerning the means of the quantitative variables. Considering the comparison of each group before and after the intervention, Wilcoxon signed-rank test was used for quantitative variables and chi-square test for qualitative variables.

\section{Ethical Considerations}

The permission for this project was issued by the Ethics Committee of the University (IR.SUMS.REC.1396.161), the province's healthcare center, and the healthcare center of Shouraab in Kohmareh-Sorkhi. The people participating in this study were required to fill out informed consent forms and were assured of the freedom to withdraw from the study at any time as well as the confidentiality of their information.

\section{Findings}

The mean age of the participants was $36.07 \pm 12.47$ years (18-55). There was no significant difference between the mean age of the participants in the intervention group $(33.91 \pm 10.84)$ and the control group (38.22 \pm 14.69$)$ $(\mathrm{p}=0.1)$. Most of the participants were male $(n=48$, $52.2 \%)$ and married $(n=67,73.6 \%)$ and did not have academic education $(n=83,90.2 \%)$. In addition, the majority of the participants did not have any information about CPR $(n=80,87 \%)$ and had never seen an unconscious person $(n=73,79.3 \%)$. There was no statistically significant difference between the two groups in terms of demographic characteristics (Table 1).

Table I Demographic Information of the Intervention and Control Groups

\begin{tabular}{|c|c|c|c|c|c|}
\hline \multirow[t]{2}{*}{ Demographic Information } & \multirow[t]{2}{*}{ Category } & \multicolumn{2}{|l|}{ Group } & \multirow{2}{*}{$\begin{array}{l}\text { Total }(n=92) \\
n(\%)\end{array}$} & \multirow[t]{2}{*}{ P-value } \\
\hline & & $\begin{array}{l}\text { Intervention Group } \\
(n=46) n(\%)\end{array}$ & $\begin{array}{l}\text { Control Group } \\
(n=46) n(\%)\end{array}$ & & \\
\hline Gender & $\begin{array}{l}\text { Male } \\
\text { Female }\end{array}$ & $\begin{array}{l}22(23.9) \\
24(26.1)\end{array}$ & $\begin{array}{l}26(28.3) \\
20(21.7)\end{array}$ & $\begin{array}{l}48(52.2) \\
44(48.8)\end{array}$ & 0.4 \\
\hline Marital status & $\begin{array}{l}\text { Single } \\
\text { Married }\end{array}$ & $\begin{array}{l}14(15.4) \\
32(35.2)\end{array}$ & $\begin{array}{l}10(11) \\
35(38.5)\end{array}$ & $\begin{array}{l}24(26.4) \\
67(73.6)\end{array}$ & 0.37 \\
\hline Education level & $\begin{array}{l}\text { Non-academic } \\
\text { education } \\
\text { Academic } \\
\text { education }\end{array}$ & $\begin{array}{l}39(42.4) \\
7(7.6)\end{array}$ & $\begin{array}{l}44(47.8) \\
2(3.2)\end{array}$ & $\begin{array}{l}83(90.2) \\
9(9.8)\end{array}$ & 0.08 \\
\hline Occupation & $\begin{array}{l}\text { Homemaker } \\
\text { Farmer } \\
\text { Jobless } \\
\text { Other }\end{array}$ & $\begin{array}{l}19(20.7) \\
12(13) \\
8(8.7) \\
7(7.6)\end{array}$ & $\begin{array}{l}15(16.3) \\
19(20.7) \\
6(6.5) \\
6(6.5)\end{array}$ & $\begin{array}{l}34(37) \\
31(33.7) \\
14(15.2) \\
13(14.1)\end{array}$ & 0.49 \\
\hline Having seen an unconscious person & $\begin{array}{l}\text { Yes } \\
\text { No }\end{array}$ & $\begin{array}{l}9(9.8) \\
37(40.2)\end{array}$ & $\begin{array}{l}10(10.9) \\
36(39.1)\end{array}$ & $\begin{array}{l}19(20.7) \\
73(79.3)\end{array}$ & 0.79 \\
\hline $\begin{array}{l}\text { Having information about } \\
\text { cardiopulmonary resuscitation }\end{array}$ & $\begin{array}{l}\text { Yes } \\
\text { No }\end{array}$ & $\begin{array}{l}7(7.6) \\
39(42.4)\end{array}$ & $\begin{array}{l}5(5.4) \\
4 I(44.6)\end{array}$ & $\begin{array}{l}12(13) \\
80(87)\end{array}$ & 0.54 \\
\hline $\begin{array}{l}\text { Desire to learn cardiopulmonary } \\
\text { resuscitation }\end{array}$ & $\begin{array}{l}\text { Yes } \\
\text { No }\end{array}$ & $\begin{array}{l}46(50.5) \\
0(0)\end{array}$ & $\begin{array}{l}44(48.4) \\
\mathrm{I}(\mathrm{I} . \mathrm{I})\end{array}$ & $\begin{array}{l}90(98.9) \\
I(1.1)\end{array}$ & 0.49 \\
\hline
\end{tabular}


The findings revealed no significant difference between the two groups' knowledge scores before the intervention. However, the intervention group's mean score of knowledge after the intervention was significantly greater compared to that before the intervention and compared to the control group. Moreover, the findings showed no significant difference between the two groups' performance scores before the intervention. However, the intervention group's mean score of performance after the intervention was significantly higher compared to that before the intervention and compared to the control group. The betweenand within-group comparisons of the mean and median scores of knowledge and performance before and after the intervention have been presented in Table 2 .

\section{Discussion}

The results of this study revealed that the majority of the participants were weak in terms of knowledge and performance regarding basic CPR before the intervention. However, their knowledge and performance improved after taking part in the teaching program. Similarly, Dasgupta et al showed the positive effect of teaching basic CPR techniques on the students' performance and knowledge in a village in West Bengal. ${ }^{32}$ Other studies have also demonstrated the effectiveness of teaching programs on CPR in different groups like unprofessional people. For instance, a three-hour training program was effective in improvement of electricians' CPR performance in Sweden. ${ }^{20}$ Furthermore, Salehi et al conducted a single-group study with a quasi-experimental design and indicated the effectiveness of teaching CPR using the combination of three methods; i.e., lecture, working with a manikin, and group discussion, in the knowledge and performance of the entourages of patients suffering from cardiovascular diseases. ${ }^{26}$ Some studies have also shown improvements in school students' knowledge and performance after participating in CPR teaching programs. ${ }^{11,23}$ Based on the results of a prospective study by Meissner et al in Germany, the students' knowledge and performance in doing CPR improved after receiving the education. ${ }^{35}$ In another quasi-experimental study in Iran, Red Crescent rescuers' and fire fighters' knowledge and performance were improved after receiving basic CPR teachings via two practical methods; i.e., movies and manikins. ${ }^{26}$ Similarly, another experimental study showed the effect of teaching basic CPR techniques using demonstration method on the improvement of performance among 50 selected military organization soldiers. ${ }^{24}$

Weak knowledge and performance among people living in rural areas is a serious warning for healthcare policymakers. Previous studies have revealed weakness in untrained people's knowledge and performance regarding basic CPR. ${ }^{23-25}$ Similarly, students living in villages had weak knowledge and performance regarding basic

Table 2 The Between- and Within-Group Comparisons of the Mean and Median Scores of Knowledge and Performance Before and After the Intervention

\begin{tabular}{|c|c|c|c|c|c|}
\hline \multicolumn{2}{|l|}{ Time } & \multirow{2}{*}{$\begin{array}{l}\text { Pretest } \\
\text { Mean士SD } \\
\text { Mean (IQR) }\end{array}$} & \multirow{2}{*}{$\begin{array}{l}\text { Posttest } \\
\text { Mean士SD } \\
\text { Mean (IQR) }\end{array}$} & \multirow[t]{2}{*}{$\mathbf{Z}^{*}$} & \multirow[t]{2}{*}{ P-value (Within Groups) } \\
\hline Group & Statistic & & & & \\
\hline Knowledge & $\begin{array}{l}\text { Intervention } \\
\text { Control }\end{array}$ & $\begin{array}{l}2.78 \pm 1.74 \\
3(2-4) \\
3.19 \pm 1.77 \\
3(2-4)\end{array}$ & $\begin{array}{l}6.78 \pm 1.23 \\
7(6-7) \\
3.24 \pm 1.84 \\
3(2-4)\end{array}$ & $\begin{array}{l}5.86 \\
0.44\end{array}$ & $\begin{array}{l}P<0.001 \\
0.66\end{array}$ \\
\hline \multicolumn{2}{|c|}{$\begin{array}{l}\text { P-value (between groups) } * * \\
\text { Effect size }\end{array}$} & $\begin{array}{l}0.24 \\
0.26\end{array}$ & $\begin{array}{l}\mathrm{P}<0.00 \mathrm{I} \\
2.26\end{array}$ & & \\
\hline Performance & $\begin{array}{l}\text { Intervention } \\
\text { Control }\end{array}$ & $\begin{array}{l}0.8 \pm 0.77 \\
\mathrm{I}(0-1) \\
1.04 \pm 0.7 \\
\mathrm{I}(\mathrm{I}-\mathrm{I})\end{array}$ & $\begin{array}{l}8.22 \pm 1.65 \\
8(7-9) \\
I .|7 \pm 0.7| \\
I(I-2)\end{array}$ & $\begin{array}{l}26.67 \\
1.73\end{array}$ & $\begin{array}{l}P<0.001 \\
0.083\end{array}$ \\
\hline \multicolumn{2}{|c|}{$\begin{array}{l}\text { P-value (between groups)** } \\
\text { Effect size }\end{array}$} & $\begin{array}{l}0.09 \\
0.33\end{array}$ & $\begin{array}{l}P<0.001 \\
5.55\end{array}$ & & \\
\hline
\end{tabular}

Notes: *Wilcoxon signed-rank test was used. **Mann-Whitney test was used. 
CPR. ${ }^{32}$ This shows the necessity of consideration of this crucial issue by healthcare systems worldwide.

In the current study, after random selection of the villages and families, each family was requested to introduce one of its members to participate in the study. The findings showed that training the family representatives improved their knowledge and performance regarding CPR. These people will be noteworthy sources in performing life support actions for their family members. Additionally, they understand their family contexts and the members' potentials and needs. Therefore, they may be able to teach the learned knowledge and actions to other family members using an understandable language and encourage them to learn and perform these activities in critical situations. Therefore, further studies are recommended to assess the teaching role of the trained individuals in rural areas and to determine the long-term effects of education on CPR performance.

The present study findings indicated that most of the participants were interested in learning CPR. Although they were busy mostly with farming and housekeeping activities, they participated in the study. This indicated the benefits and feasibility of public education about CPR in rural areas.

The present quasi-experimental study with controlled pre/posttest design was conducted with an eight-week interval. One of the strengths of this study was being one of the first investigations on training adults living in rural areas regarding basic CPR techniques. Another significance of this study was the utilization of the CPR guideline specific for lay rescuers. The two-group design of this study was indeed another advantage. However, this research project had limitations, too. One of the limitations was the close relationships among the residents of each village. Therefore, in order to prevent data contamination between the intervention and control groups, random allocation was done based on villages rather than individuals. Another study limitation was the impossibility of blinding due to the nature of the educational intervention.

\section{Conclusion}

The findings of the present study showed that people's knowledge and performance regarding basic CPR was weak before the intervention, which is a serious issue in nature. This important issue should be considered by healthcare policymakers due to the distance of rural areas form healthcare centers. Besides, the findings revealed that the four-hour teaching program for basic CPR could improve the villagers' knowledge and performance and could be effective in the cultural context of the rural areas. Hence, using similar teaching methods to enhance villagers' knowledge and performance is suggested. Moreover, suitable teaching methods should be studied to reinforce the acquired knowledge and performance and prevent them from being forgotten over time.

\section{Data Sharing Statement}

Any kind of data will be available upon request. All data have been included in the manuscript. In case any specific kind of data that does not include the participants' confidential information is requested, it can be provided. Data will be available upon request from the corresponding author. Data will be available until one year after publication.

\section{Acknowledgments}

This manuscript was extracted from the MSc thesis written by Zamanallah Hajinasab and financially supported by ViceChancellor for Research and Technology of Shiraz University of Medical Sciences (grant No. 1396-01-0815503). Hereby, the authors would like to express their special thanks to the Center for Development of Clinical Research of Nemazee Hospital and Dr. Marjan Faghih for her contribution to data analysis and Dr. Sezaneh Haghpanah for her assistance in proposal design. They would also like to appreciate Ms. A. Keivanshekouh at the Research Improvement Center of Shiraz University of Medical Sciences for improving the use of English in the manuscript. Thanks also go to the Vice-Chancellor for Research and Technology of Shiraz University of Medical Sciences, community healthcare center of Kohmareh-Sorkhi, and all participants for their cooperation in the study.

\section{Disclosure}

The authors report no conflicts of interest in this work.

\section{References}

1. Hayashi M, Shimizu W, Albert CM. The spectrum of epidemiology underlying sudden cardiac death. Circ Res. 2015;116(12):1887-1906. doi:10.1161/CIRCRESAHA.116.304521

2. Taniguchi D, Baernstein A, Nichol G. Cardiac arrest: a public health perspective. Emergency Med Clin. 2012;30(1):1-12. doi:10.1016/j. emc.2011.09.003

3. Daya MR, Schmicker RH, Zive DM, et al. Out-of-hospital cardiac arrest survival improving over time: results from the Resuscitation Outcomes Consortium (ROC). Resuscitation. 2015;91:108-115. doi:10.1016/j.resuscitation.2015.02.003

4. Chugh SS. Sudden cardiac death in 2017: spotlight on prediction and prevention. Int J Cardiol. 2017;237:2-5. doi:10.1016/j.ijcard.2017.03.086 
5. Berdowski J, Berg RA, Tijssen JG, Koster RW. Global incidences of out-of-hospital cardiac arrest and survival rates: systematic review of 67 prospective studies. Resuscitation. 2010;81(11):1479-1487. doi:10.1016/j.resuscitation.2010.08.006

6. Greif R, Lockey AS, Conaghan P, et al. European resuscitation council guidelines for resuscitation 2015: section 10. Education and implementation of resuscitation. Resuscitation. 2015;95:288-301.

7. Kleinman ME, Brennan EE, Goldberger ZD, et al. Part 5: adult basic life support and cardiopulmonary resuscitation quality: 2015 American Heart Association guidelines update for cardiopulmonary resuscitation and emergency cardiovascular care. Circulation. 2015;132 (18 suppl 2):S414-S35. doi:10.1161/CIR.0000000000000259

8. Aghamohammadi S, Kazemi E, Khosravi A, Kazemeini H. The trend of ten leading causes of death in the Islamic Republic of Iran, 2006-2011. Iran J Epidemiol. 2017;12(4):1-11.

9. Sarrafzadegan N, Mohammadifard N. Cardiovascular disease in Iran in the last 40 years: prevalence, mortality, morbidity, challenges and strategies for cardiovascular prevention. Arch Iran Med. 2019;22:4.

10. Travers AH, Perkins GD, Berg RA, et al. Part 3: adult basic life support and automated external defibrillation: 2015 international consensus on cardiopulmonary resuscitation and emergency cardiovascular care science with treatment recommendations. Circulation. 2015;132 (16 suppl_1):S51-S83. doi:10.1161/CIR.0000000000000272

11. Alimohammadi N, Baghersad Z, Marofi M. Comparative study on the effectiveness of cardiopulmonary resuscitation by two methods of role playing and displaying video on knowledge and performance of high school students. JNE. 2017;6(3):24-30. doi:10.21859/jne-06034

12. Perkins GD, Handley AJ, Koster RW, et al. European resuscitation council guidelines for resuscitation 2015: section 2. Adult basic life support and automated external defibrillation. Resuscitation. 2015;95:81-99.

13. Granser JT, Lefering R, Koster RW, et al. EuReCa ONE-27 Nations, ONE Europe, ONE Registry: a prospective one month analysis of out-of-hospital cardiac arrest outcomes in 27 countries in Europe. Resuscitation. 2016;105:188-195. doi:10.1016/j.resuscitation.2016. 06.004

14. Ong MEH, Do Shin S, De Souza NNA, et al. Outcomes for out-ofhospital cardiac arrests across 7 countries in Asia: the Pan Asian Resuscitation Outcomes Study (PAROS). Resuscitation. 2015;96:100-108. doi:10.1016/j.resuscitation.2015.07.026

15. Dolatabadi AA, Memary E, Shojaee M. Survival and outcomes following cardiopulmonary resuscitation; a descriptive study in Iran J Emergency Pract Trauma. 2017;3(1):22-25. doi:10.15171/jept. 2017.09

16. Dianati M, Assari-Maraghi A, Paravar M, Gilasi H. Bystander's cardiopulmonary resuscitation rate and related factors in Kashan, Iran in 2014. Feyz J Kashan Univ Med Sci. 2015;19.

17. Hansen CM, Kragholm K, Pearson DA, et al. Association of bystander and first-responder intervention with survival after out-of-hospital cardiac arrest in North Carolina, 2010-2013. JAMA. 2015;314 (3):255-264. doi:10.1001/jama.2015.7938

18. Kanstad BK, Nilsen SA, Fredriksen K. CPR knowledge and attitude to performing bystander CPR among secondary school students in Norway. Resuscitation. 2011;82(8):1053-1059. doi:10.1016/j.resuscitation.2011. 03.033

19. Cho GC, Sohn YD, Kang KH, et al. The effect of basic life support education on laypersons' willingness in performing bystander hands only cardiopulmonary resuscitation. Resuscitation. 2010;81 (6):691-694. doi:10.1016/j.resuscitation.2010.02.021
20. Lerjestam K, Willman A, Andersson I, Abelsson A. Enhancing the quality of CPR performed by laypeople. Australas $J$ Paramed. 2018;15:4. doi:10.33151/ajp.15.4.594

21. Seyedbagheri S, Sadeghi T, Kazemi M, Nadimi AE. Dispatcherassisted bystander cardiopulmonary resuscitation (Telephone-CPR) and outcomes after out of hospital cardiac arrest. Bull Emerg Trauma. 2019;7(3 JUL):307-314. doi:10.29252/beat-070315

22. Mohsen Pour M, Imani Z, Abdol Karim M. Effect of CPR training on the knowledge of nursing staff and CPR team members in a hospital in Kerman province. J Nurs Mid Kerman. 2009;18(1-2):1-7.

23. Azarpoor Z, Masoompour A, Jambarsang S. The effect of cardiopulmonary resuscitation training on basic life support knowledge and performance among primary school students. J Nurs Educ. 2015;4:3.

24. Chegeni Z, Aliyari S. The effect of basic cardiopulmonary resuscitation training, by the presentation method, on the performance of soldiers in military units. Mil Caring Sci. 2018;4(4):227-235. doi:10.29252/ mcs.4.4.227

25. Fujie K, Nakata Y, Yasuda S, Mizutani T, Hashimoto K. Do dispatcher instructions facilitate bystander-initiated cardiopulmonary resuscitation and improve outcomes in patients with out-of-hospital cardiac arrest? A comparison of family and non-family bystanders. Resuscitation. 2014;85(3):315-319. doi:10.1016/j.resuscitation.2013.11.013

26. Salehi S, Zonoori S, Tabarsi B, Ghanbarian H, Nasiri M. The effect of cardiopulmonary resuscitation education through compound method on knowledge and performance of entourages of patients with cardiovascular diseases. J Nurs Educ. 2016;5(3):10-16. doi: $10.21859 /$ jne- 05032

27. Rambod M, Sharif F, Khademian Z. The impact of the preceptorship program on self-efficacy and learning outcomes in nursing students. Iran J Nurs Midwifery Res. 2018;23(6):444. doi:10.4103/ijnmr.IJNMR_67_17

28. Søreide E, Morrison L, Hillman K, et al. The formula for survival in resuscitation. Resuscitation. 2013;84(11):1487-1493. doi:10.1016/j. resuscitation.2013.07.020

29. Bhanji F, Donoghue AJ, Wolff MS, et al. Part 14: education: 2015 American Heart Association guidelines update for cardiopulmonary resuscitation and emergency cardiovascular care. Circulation. 2015;132 (18_suppl_2):S561-S73. doi:10.1161/CIR.0000000000000268

30. Lee E-K, Kim O-H, Kim E-M. The effect of CPR education in a rural community. J Korean Acad Soc Nurs Educ. 2010;16(1):121-128. doi:10.5977/JKASNE.2010.16.1.121

31. Park JH, Ro YS, Do Shin S, Song KJ, Hong KJ, Kong SY. Dispatcherassisted bystander cardiopulmonary resuscitation in rural and urban areas and survival outcomes after out-of-hospital cardiac arrest. Resuscitation. 2018;125:1-7. doi:10.1016/j.resuscitation.2018.01.026

32. Dasgupta A, Banerjee S, Goswami S, Karmakar N, Das A, Das S. Effectiveness of learning intervention on basic life support and cardio pulmonary resuscitation among school children in a village of West Bengal. Editorial Office. 2015;1:01.

33. Golboni F, Nadrian H, Najafi S, Shirzadi S, Mahmoodi H. Urbanrural differences in health literacy and its determinants in Iran: a community-based study. Aust J Rural Health. 2018;26(2):98-105. doi:10.1111/ajr.2018.26.issue-2

34. Hazinski MF, Nolan JP, Aickin R, et al. 2015 International Consensus on Cardiopulmonary resuscitation and emergency cardiovascular care science with treatment recommendations. Circulation. 2015;132:S1. doi:10.1161/CIR.0000000000000270

35. Meissner TM, Kloppe C, Hanefeld C. Basic life support skills of high school students before and after cardiopulmonary resuscitation training: a longitudinal investigation. Scand J Trauma Resusc Emerg Med. 2012;20(1):31. doi:10.1186/1757-7241-20-31 


\section{Publish your work in this journal}

The Open Access Emergency Medicine is an international, peerreviewed, open access journal publishing original research, reports, editorials, reviews and commentaries on all aspects of emergency medicine. The manuscript management system is completely online

and includes a very quick and fair peer-review system, which is all easy to use. Visit http://www.dovepress.com/testimonials.php to read real quotes from published authors.

Submit your manuscript here: https://www.dovepress.com/open-access-emergency-medicine-journal 